Escribano Belmar, Beatriz.

Contratada Predoctoral, Universidad de Castilla-La Mancha, Departamento de Arte, Grupo de Investigación "Interfaces Culturales; Arte y Nuevos Medios".

\title{
Real-virtual. Una arqueología de los medios a partir de los procesos electrográficos de [re]producción, transmisión e impresión de imágenes surgidos desde la segunda mitad del S.XX.
}

TIPO DE TRABAJO

Comunicación.

PALABRAS CLAVE

Arqueología de los Medios, Media Art, Arte Digital, Arte Pre-digital, Copy Art.

KEY WORDS

Media Archaeology, Media Art, Digital Art, Pre-digital Art, Copy Art.

RESUMEN

La presente comunicación propone revisar la relación entre lo real y lo virtual en el desarrollo de las manifestaciones artísticas, mediante Arqueología de los Medios de las propuestas artísticas originadas del uso de los procesos automáticos de [re]producción, transmisión e impresión de imágenes desarrollados a finales del S.XX y principios del S.XXI, y cuyo uso generó varios movimientos artísticos underground como vanguardias experimentales desarrolladas ajenas a la historiografía oficial, principio del arte digital y raíz del Media Art.

Estas propuestas artísticas pre-digitales y digitales manifiestan lo que supuso para el artista tropezar, por primera vez en los años 60, con las primeras máquinas automáticas de la imagen, comúnmente fotocopiadora, video y ordenador, quién las utilizó como herramientas renovadoras de las iconografías rompiendo muchos de los conceptos tradicionales del arte y siendo base ya de la transformación de los paradigmas analógicos a los digitales. Se evidencia la búsqueda del artista, bajo su instinto lúdico, de la experimentación como modo de conocer, no sólo la propia máquina, sino todo lo que le rodea a través de la mirada de ésta como el encuentro más erótico con la tecnología, aquella que va más allá de la huella, y permite nuestra representación instantánea y ubicua.

El objetivo será reivindicar un arte digital que tiene sus raíces en las tecnologías automáticas partiendo de las Colecciones y Archivos de Arte Contemporáneo de Cuenca (CAAC), especialmente del Museo Internacional de Electrografía (MIDE), el único lab-museo que existe a nivel mundial dónde se encuentran las obras de los principales artistas del Arte Electrográfico con más de 1800 obras creadas con procesos relacionados con estas tecnologías. Un lab-museo para la conservación de obra y la creación mediante la investigación, que ejemplifica el paso del arte analógico-tangible al digitalintangible con obras de Arte Electrográfico, Digital y Multimedia.

\section{ABSTRACT}

The current comunication intends to review the relationship between the real and the virtual in the development of artistic expression, from the Media Archaeology of the underground movements originated by the use of automatic processes of [re]production, transmission and printing of images at the end of the XX century and early XXI century, as experimental vanguard outside the official historiography, beginning of the digital art and root of Media Art. 
These pre-digital and digital artistic proposals show what supposed for the artist the first stumble with automatic machines of the image, commonly called photocopier, video and computer, which in his hands became innovative tools of the iconography breaking many of the traditional concepts of art and being base of the transformation from analog to digital paradigms. These works reveal the search by the artist, thanks to its playful instinct, of the experimentation as a way to know not only the machine itself, but everything around it through the most erotic intersection with technology, that transcends the tread and allows our instant and ubiquitous representation.

The main objective claim about a digital art that has its roots in automatic technologies emerged in the sixties, based on the Collections and Archives of Contemporary Art in Cuenca (CAAC), especially the International Museum of Electrography (MIDE) the unique open lab-museum in the world where there are some of the main artworks of the Electrographic Art, with more than 1,800 works created with processes related to technology. A lab-museum to preserve and create work through researching, which exemplifies the pass from analog-tangible to digital-intangible artworks.

\section{CONTENIDO}

\section{INTRODUCCIÓN}

En la actualidad, uno de los objetivos principales de las teorías relacionadas con el Media Art consiste en realizar Arqueología de los Medios, pues "[...] al centrarse en el arte reciente teniendo como fondo el contexto de los acontecimientos históricos, es posible analizar mejor cuáles aspectos son nuevos y cuales son heredados en el media art" ${ }^{\prime 1}$. Esta metodología es utilizada para entender el presente y sus logros, permitiendo recrear y utilizar las mismas mediaciones en los contenidos que se han utilizado en el pasado, remodelando su contexto específico para entender los medios artísticos actuales, a través de la reflexión y análisis.

Bajo esa visión, es necesario y casi urgente, realizar Arqueología de algunas propuestas artísticas olvidadas por la teoría, estética e historia oficial del arte y que suponen el origen de muchos de los paradigmas fundamentales del arte digital, y de modo más general, del Media Art". "El objetivo es abrir la historia del arte para incluir formas de arte realizado con los media de las ultimas décadas y las formas de arte contemporáneo. Principalmente fotografía, cine, video y pequeña historia de los media de los años 60 hasta los 80 , los artista de los media están utilizando amplias áreas digitales (incluyendo net art, interactivo, generativo, y telemático)." ${ }^{3}$.

Como es razonable, el descubrimiento de nuevas herramientas siempre ha obligado al hombre a reciclarse y aprender su manejo, y como efecto, se desarrolla una nueva concepción del mundo, de las cosas y se produce un cambio cultural, social, político y económico que afecta en la formación de nuevas corrientes artísticas. De este modo, son los procedimientos tanto electrográficos como predigitales de [re]producción, transmisión e impresión de imágenes la base fundamental para la transformación que se produce en los paradigmas del arte analógico a los digitales y que evolucionan en el contexto de lo real a través de las primeras máquinas automáticas analógicas, para finalizar en el ámbito de las tecnologías digitales y la naturaleza virtual. Unos procesos que surgen en los años 60 generando de su uso, por un lado, una serie de movimientos artísticos underground que actuaron como vanguardias propiamente experimentales, entre ellos Copy Art, Mail Art y Fax Art, desarrollados en paralelo pero de modo subterráneo y alternativo a las que históricamente se conocen como Segundas Vanguardias. Por otro lado, concibieron, según el modo de uso de la máquina, un lenguaje propio y unas técnicas artísticas características que fueron utilizadas, asimismo, por muchos artistas de otros programas creativos como eran la estampa, la pintura o incluso la fotografía.

\section{DESARROLLO DE LOS PROCESOS ELECTROGRÁFICOS AL ARTE DIGITAL.}

Es la década de los años 60 la que se convierte en testigo de las grandes rupturas en los paradigmas del arte tradicional que han instituido la base de las principales características del arte digital. Así, el origen de esta ruptura es la aparición en el mercado de tres tecnologías automáticas de generación, producción y registro de la imagen: 1960 para la primera máquina xerográfica automática Xerox 914 (comúnmente conocida como fotocopiadora), 1964 para el Personal Computer IBM System/360 y 1967 para la Portapak de video Sony D-2400. Las tres tecnologías, que llegan al mercado con una finalidad "ofimática" o "doméstica", y que por tanto, son mucho más accesibles al público cotidiano; desatan intereses similares en los artistas. De hecho, se originan prácticas

\footnotetext{
1 "Beyond that: by focusing on recent art against the backdrop of historic developments, it is posible to better analyze which aspects are new and which aspects inherited in media art". GRAU, Olivier (ed.): Media Art Histories. The MIT Press. Cambrige, Massachussets / London, England. 2007. p.8

${ }^{2}$ Utilizaremos la denominación anglosajona de Media Art durante todo el texto porque como término, engloba de manera más adecuada el conepto al que se refiere, ya que su traducción al castellano <arte de los medios> puede conducir a equivocos.

3 "The goal is to open up art history to include media art from recent decades and contemporary art forms. Resides photography, film, video, and little known media art history of the 1960s to the '80s, today media artists are active a wide range of digital areas (including net art, interactive, genetic, and telematic art)". GRAU, Olivier (ed.): Media Art Histories. The MIT Press. Cambrige, Massachussets / London, England. 2007.p.1
} 
interdisciplinares entre ellas, como es el ejemplo del artista alemán Franz John quién, en los años 80, utiliza la máquina xerográfica para generar obras que posteriormente compone a través del video; o la artista holandesa Lieve Prins quien introduce directamente una cámara de video en la caja del barrido lumínico de una máquina xerográfica para mostrar la mirada del aparato o incluso concibe diversos originales con las tecnologías xerográficas digitales que posteriormente compone a través del ordenador.

Son numerosos, igualmente, los grupos y centros artísticos creados con el objetivo de investigar sobre ellas. Cabe destacar el centro Generative Systems Department, que comenzó como un programa desarrollado por un grupo de artistas asociados al Art Institute de Chicago, principalmente la pionera Sonia Landy Sheridan, al final de los años 60 con el fin de inquirir en las posibilidades artísticas del uso de las fotocopiadoras, el ordenador y el video.

El uso de las tres engendró una revolución en los paradigmas artísticos que venía gestándose desde los movimientos vanguardistas Dadá y Fluxus, entre ellos: la idea del proceso como obra final, la naturaleza múltiple y no única de ésta, y el surgimiento de una interfaz que media entre el artista - obra y que conecta directamente con el arte digital. Pese a esto, la valoración dada a las propuestas artísticas realizadas con ellas ha sido muy diferente ya que dentro de la historia oficial sólo el video tiene un movimiento estimado como es el videoarte. Introducido en contraposición a la televisión, se desarrolla como una corriente artística y experimental y como corriente que se pone al servicio de otras prácticas efímeras de vanguardia como la Perfomance o el Happening, actuando como registro. "Rápidamente fue el TRANSITAR. En los tiempos de los transformers y de los mutantes, el video comprendió rápidamente su vocación: no debía constituirse en una isla, en un espacio puro y autosuficiente. Como recién llegado podría haberse pensado que se situaría pasivamente a la cola de la secuencia pintura-foto-cine, pero el video es contemporáneo al espíritu post y trans-vanguardista y se situó entre las culturas que le precedieron, constituyéndose así en un parámetro obligado para todas las culturas visuales y audiovisuales, en un corredor de éstas, y en el espacio natural desde el cual se puede hablar a propósito de cualquiera de ellas con propiedad"4. Por otro lado, respecto al ordenador, aunque no se considera oficialmente el Computer Art como movimiento, casi todas las producciones que giran en torno a la tendencia del Media Art tienen como base la creación con ordenador: virtual art, cibernetic art, visualization art, generative art, net art, etc; por lo que ocupa su lugar por derecho propio.

Sin embargo, y muy al contrario que las anteriores, las practicas artísticas engendradas del uso de las tecnologías eléctricas y posteriormente electrónicas y digitales de [re]producción y transmisión de la imagen (principalmente fotocopiadora xerográfica automática y telefax) que son especialmente reflejo de las pugnas propuestas por la vanguardia y de las reflexiones expuestas por teóricos como Umberto Eco, Marshal McLuhan, Paul Virilio o Baudrillard, entre otros, se hallan, aún hoy, sin la valoración que le concierne por su influencia en los movimientos de vanguardia y en la propia fundamentación del arte digital.

\section{ORIGEN Y PROPOSICIONES. ESTRATEGIAS CREATIVAS Y DE INVESTIGACIÓN}

El origen de la máquina automática de reproducción, comúnmente conocida como fotocopiadora, que llega al mercado en 1960, está ligado a dos métodos o procedimientos fundamentales. Por un lado, se basa en el "Difusión-Transfer-Reversal o DTR" creado por la química Edith Waydes de la compañía Agfa y, por otro lado, en el procedimiento electrofotográfico indirecto de reproducción descubierto el 22 de Octubre de 1938 por Chester F.Carlson, cuya primera copia fue un texto donde podía leerse la fecha y el lugar "10/22/38 Astoria" y que utilizaba cargas electroestáticas y tóner seco en lugar de otro productos químicos líquidos. Este último proceso fue desarrollado por la Compañía fotográfica Haroid que posteriormente se llamó Xerox (cuyo nombre proviene de la propia técnica de copiado en seco denominada xerografía). Sin embargo, sobre todo en Europa, se cree que existió un descubrimiento anterior que probablemente sea el origen del proceso de Chester Carlson y que fue registrado por el belga Marcel Demeulenaere el 11 de Junio de 1932 como "procédé de phtographie sans developement".

De este modo, una máquina cuyos principios técnicos estaban basados en la óptica y en la electricidad para reproducir lumínicamente imágenes planas como eran las primeras xerografías analógicas, acabará transformándose hasta convertirse en una máquina capaz de generar, producir, crear (-y no copiar o reproducir) nuevas imágenes en código numérico a partir de imágenes y objetos bi o tridimensionales gracias a la tecnología digital. En su evolución artística pueden observarse, en primer lugar, una etapa de aproximación y tanteo que parte del descubrimiento de la máquina por los artistas pioneros (1960-1970 aprox.), una segunda etapa basada en la investigación mediante las primeras metodologías creativas (1975-1990 aprox.) y, finalmente, una etapa de experimentación totalmente digital (1990 en adelante).

Creada con el objetico comercial de copiar documentos de un modo más ágil, es precisamente éste origen el que hace que muchos artistas mantengan su primer encuentro con la máquina. Es el caso de la artista pionera Sonia L.Sheridan, quién al final de los años 60 estaba envuelta con sus estudiantes en la creación de posters para su distribución durante la convención democrática y que "Frustrados por el tiempo requerido por la mayoría de los procesos, buscó maneras más rápidas para crear imágenes en serie. Primero quedando intrigada con la fotocopiadora Xerox, y después, pasar a la $3 \mathrm{M}$ Thermo-Fax, Sheridan llevó su creatividad única a la

\footnotetext{
${ }^{4}$ OLHAGARAY LLANOS, Néstor: Del video-arte al net-art. Editorial LOM, Santiago de Chile. 2002. p.9
} 
manipulación de la máquina para producir arte. ${ }^{\prime \prime}$. Es así como se transforma en una herramienta innovadora que trabaja en la dirección de las proclamas teóricas del momento: desauratización del objeto artístico, imagen múltiple, fragmentación de la realidad, orientación sobre el proceso creativo, desmaterialización del objeto o incluso la teoría de que la realidad resultante es fruto de la velocidad o dromología ( Paul Virilio, "Speed and Politics". 1977). Esta última teoría es fundamento de una de las características principales de esta máquina: su instantaneidad ya que "En un mundo de café instantáneo, películas instantáneas, y loterías instantáneas, la copiadora ofrece creatividad instantánea- sin limitaciones." ", "El arte instantáneo ha nacido. Rápido, casi más, que una Polaroid, capaz de ver y evaluar tu trabajo, hacer los ajustes necesarios a la máquina, y luego comenzar de nuevo."” Unas propuestas que brotaron como respuesta a un contexto que deseaba un arte automático e instantáneo, donde la noción de tiempo y espacio y su medida, cambian radicalmente y eso es reflejado en la tecnología del tiempo, por primera vez el artista pulsa un botón y se obtiene una imagen en tiempo real.

Cuando la máquina fotocopiadora automática llega al mercado se producen, a grandes rasgos, dos situaciones. En unos casos, la máquina, con su función ofimática, es colocada en establecimientos comerciales dedicados a la copia doméstica y, por tanto, el artista con menos posibilidades económicas debe crear en un contexto inusual. "Arte Instantáneo para todo el mundo. Bienvenido a la era del Arte de la Copia. Ahora cualquier persona tiene el potencial de ser un artista o diseñador con sólo pulsar un botón. Esa máquina fotocopiadora de oficina, puedes dar por sentado que pasa a ser nada menos que una herramienta de creación de imágenes al instante. Un sueño del artista durante siglos, es suyo por sólo unos centavos por ejemplar." ${ }^{8}$. En otro casos, ésta entra en el estudio del artista que no posee ningún conocimiento precedente sobre la máquina, y transforma este espacio en un lab (laboratorio y no taller), y a él mismo en un investigador-experimentador considerando el arte de estos artistas como tributo al modelo de artista en la época digital que valora lo nuevo y lo experimental.

El uso de esta máquina con fines artísticos y por tanto, subvirtiendo totalmente su principal función comercial, da lugar a una serie de procesos automáticos de [re]producción, transmisión e impresión de la imagen que generaron tres usos diversos de la misma tecnología. Por un lado, se le da un uso totalmente experimental e investigativo que conecta directamente con ese espíritu radicalmente experimental del arte digital y que en este caso da lugar al desarrollo de varios movimientos artísticos (Copy Art, Mail Art y Fax Art). Por otro lado, un uso aprovechando únicamente el lenguaje artístico característico de ésta máquina, pero cuya obra final acaba dentro de los parámetros de otras prácticas como el grabado, o incluso dentro del diseño editorial o publicitario. Y finalmente, un uso únicamente como técnica dentro de otros procesos artísticos como puede ser simplemente la copia en un proceso de collage.

Es precisamente el uso experimental y radical de la máquina el que da lugar a uno de los movimientos principales conocido como Copy Art, aunque también ha sido designado como Xerox Art, Electrostatic Art, Electrografía o Electrocopia, sin que ninguna de sus denominaciones haga alusión a su verdadero potencial o innovación creativa. Este movimiento fue evolucionando con el propio progreso de la máquina analógica a la digital transformando el proprio proceso creativo como modo de reflexión "Los especialistas producen productos, mientras que los pensadores producen procesos. ${ }^{\prime \prime}$. El proceso creativo se basa, así, en la metodología procesual denominada "research-creation" en la que una forma única de "conocer" o "aprender" es "hacer". "Es evidente que la tecnología permite el desarrollo del proceso de toma de imagen. El paisaje interior y la exposición de la máquina es un ejemplo de una interacción del artista con las herramientas electrónicas para generar y hacer el proceso de la imagen." ${ }^{10}$.

\footnotetext{
${ }^{5}$ Frustrated by the time required for most art processes, she sought speedier ways to create serial images. First becoming intrigued with a Xerox photocopier, and then moving on to the 3M Thermo-Fax, Sheridan brought her unique creativity to the manipulation of the machine to produce her art.". The Art of Sonia Landy Sheridan. SHERIDAN, Sonia L.: Art's Passionate Pilgrim. Hood Museum of Art, USA. 2009.

6 "In a world of instant coffee, instant movies, and instanat lotteries, the copier offers instar creativity- withing limitations." FIRPO, Patrick; LESTER, Alexander; KATAYANAGI, Claudia: COPYART The first complete guide to the copy machine. Horseguard Lane Productions, Ltd. Richard Marek Publishers, New York. 1978. p.10

7 "Instant art is born. Quicker, even, than Polaroid you are able to see and evaluate your work, make the necessary adjustments to the machine, and then start again" ${ }^{\prime 7}$ FIRPO, Patrick; LESTER, Alexander; KATAYANAGI, Claudia: Ibidem, p.87

8 "Instant art for everyone. Welcome to the age of Copy Art. Now anyone has the potential to be an artist or designer at the push of a button. That office-copying machine you may take for granted happens to be no less than an instant image-making tool. A dream of artist for centuries, it's yours to use for just pennies per copy.". FIRPO, Patrick; LESTER, Alexander; KATAYANAGI, Claudia: Ibidem p.7 "Specialists produce products, while thinkers produce processes". LANDY SHERIDAN, Sonia en SIKKEMA, Brent: The Inner Landscape and the Machine: A Visual Studies Workshop Traveling Exhibition of the Work of Sonia Landy Sheridan. Visual Studies Workshop, Rochester, NY. 1974.

10 "Clearly the technology permits the unfolding of the image making process. The inner landscape and the machine exhibition is an example of one artist's interaction with electronic tools to generate and image making process". Idem
} 


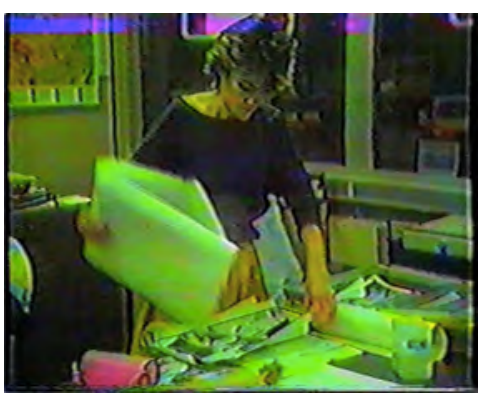

Ilustración 1. Frame de video: Lieve Prins haciendo pruebas con la máquina en el laboratorio.

Este "research-creation" (investigación-creación) es una categoría dentro de las ciencias sociales y las humanidades que habla de los medios contemporáneos así como de los nuevos modos de conocer como metodología que implica experimentar cosas constantemente. En este tipo de obras, el creador-investigador que conecta directamente con el creador digital, utiliza este método para, en un primer contacto creativo, adquirir conocimiento sobre la máquina automática y sus limites mediante la subversión de normas: "Uso la tecnología de una máquina fotocopiadora en cierto modo para forzar una discusión productiva con la máquina, forzándola para hacer cosas nuevas, entonces, a través del trabajo continuo con el medio, se desarrolla una relación creativa."11 y a partir de ahí, aprender y evaluar, a través del modo ensayo y error, anticipando acciones que detonen nuevos caminos a seguir en el camino investigación-creación. "Desde el momento en que pusieron sus manos en una de las muchas máquinas diferentes que pasaron por las aulas, desafiaron a las nociones comunes del uso correcto de la tecnología y se expandieron, distorsionaron, y transformaron sus capacidades como medio de percepción, la apertura de una gran variedad de perspectivas sin descubrir a dimensiones inimaginables del nuevo mundo electrónico"12.
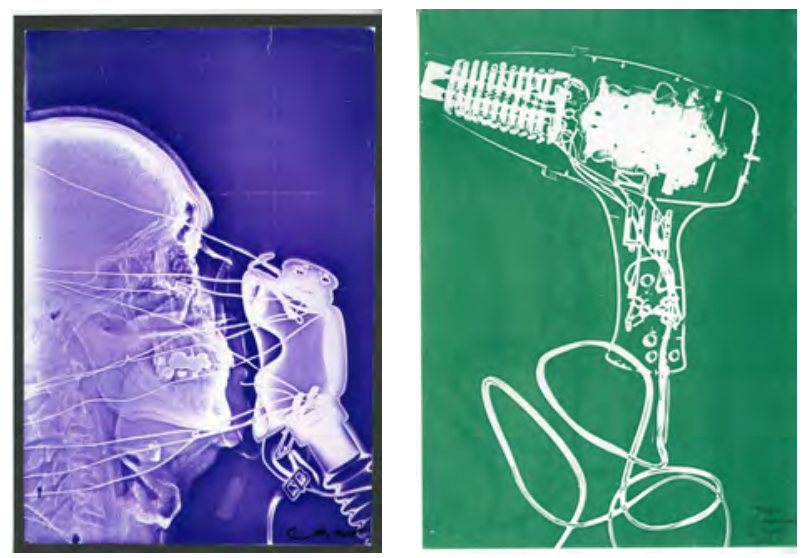

Ilustración 2. Obras realizadas por Cejar mediante Electrorradiografía, la combinación de los Rayos X con una máquina fotocopiadora o xerográfica. 1984. Colección MIDE

De este modo, el artista juzga los resultados, sopesa su valor o entidad artística, su certeza en la expresión y la forma. Y, a través de sus propias conclusiones, los artistas construyeron un ambiente de pura reflexión teórica que presumía las características de las obras creadas posteriormente. Hay que destacar que, de modo general, los artistas del Copy Art no buscaban un discurso artístico concreto, sino experimentar y buscar nuevos resultados estéticos mediante un proceso basado en la pulsión lúdica del ser, de la creación como juego. "[...] $Y$ es la consideración que el proceso productivo, o mejor, el recorrido productivo de estas obras se presenta como un recorrido lúdico.[...], estos autores no dejan de destacar que la producción artística debe permanecer como investigación, una investigación que tiene muchas características del juego, a través del cual toma control del las cosas modificándolas, haciéndolas "más cercanas a sí mismo" ${ }^{\prime 13}$. Y que además, tiene que ver mucho con la metodología "Do-It-Yourself" apretando simplemente un botón.

\footnotetext{
11 "If I use the technology of a photocopying machine in certain ways to force a production argument with the machine, by forcing it to do new things, then, through the continuing work with the medium, a creative relationship develops.". HUEMER, Peter: Photocopy Medium: From reproduction to production with analogue and digital photocopiers. 1998.

${ }_{12}^{12}$ "From the moment they got their hands on one of the many different machines that passed through the classroom, they challenged common notions of the right use of technology and expanded, distorted, and transformed its capabilities as a means of perception, opening a plethora of vistas to the undiscovered, unimagined dimensions of the new electronic world.". SHERIDAN, Sonia L.: Art at the Dawning of the Electronic Era. Generative Systems. Lonesome Press, Hanover. 2014. p.5

13 "[...]Ed è la considerazione che il processo produttivo, o meglio il percorso produttivo di queste opere si presenta come un percorso ludico. [...] questi autori non mancano di sottolineare come la produzione artistica debba presentarsi come ricerca, una ricerca che molte caratteristiche del gioco, attraverso il quale ci si impadronisce delle cose modificandole, rendendole più "vicina a sè . BARBIERI, Daniele:
} 
Del uso de la máquina también surgen propuestas que la utilizan de un modo menos innovador para seguir un programa fotográficos, publicitario o pictórico determinante de un artista, y que por tanto, sólo hacen uso del lenguaje artístico que les proporciona la máquina o simplemente de su técnica.

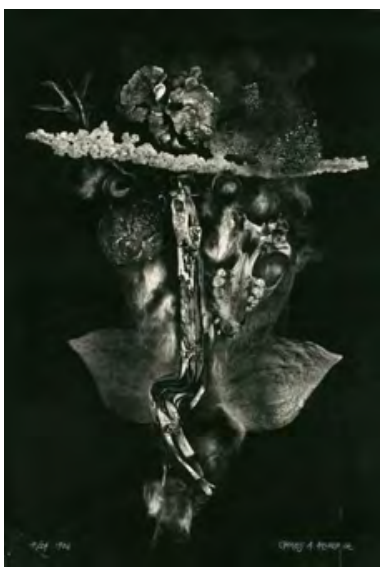

Ilustración 3. Charles Arnold Jr. None II. 1986. Colección MIDE

Una de las rupturas paradigmáticas que se produce en estas creaciones y que fundamentan la creación digital es la aparición de una interfaz que media en la creación: la pantalla o cristal, en este caso horizontal, dónde el artista coloca los diversos elementos que serán desmaterializados por el barrido de la luz de la máquina. "Una interfaz une y separa simultáneamente dos mundos muy distintos: los mundos de los sujetos creativamente activos -ya sean perceptores primarios o productores estéticos en un sentido inmediato-, por una parte, y los mundos de los aparatos y programas por otra. "14. El cristal se convierte en un "teatro horizontal", como lo llamaba la artista holandesa Lieve Prins, sobre el que ocurren cosas, y que se relaciona con el concepto de "Plano Horizontal" de Leo Steinberg, quién establece que el plano horizontal es el paso de la ventana de ver tradicional del lienzo al plano de producción, que funciona a modo de membrana conectando la naturaleza de la máquina, fría, electrónica con el cuerpo, caliente, analógico. Un intermediario entre las personas y la interfaz como elemento de comunicación y conocimiento. Es la frontera entre el espacio de representación y la del usuario o artista. A través de ella, el mundo real se transforma en un mundo desmaterializado por la luz, que en el caso de las máquinas analógicas, se transforma en materia de nuevo sobre el papel, pero transmutada por el propio lenguaje de la máquina, y su propia gramática o metalenguaje; y que las máquinas digitales permite la opción de convertir su naturaleza completamente en virtual.

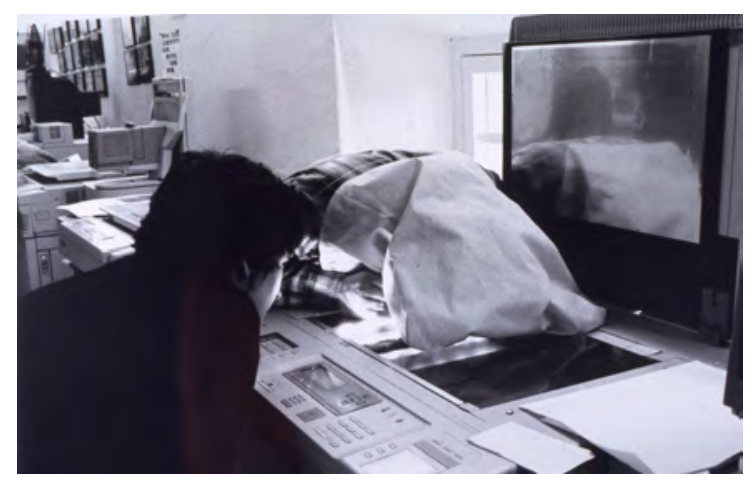

Ilustración 4. Artistas creando en el laboratorio del Museo Internacional de Electrografía (MIDE).

Estas propuestas rompen con la estética tradicional, dejando de considerar la obra o el artista como centro de la creación y dando interés hacia el propio proceso, el espacio o el público. Es así como la importancia radica también en que "La producción se convierte en un subproducto y no en un fin en sí mismo" ${ }^{\text {"15 }}$ pasando de la "imagen-objeto" tradicional a la "imagen-proceso" como se puede ver en la obra The faxed battery del japonés Marugiro, una impresión xerográfica de un proceso realizado por una máquina de

Al di là del concettuale, dalla tecnica in poi. Presentación de la exposición Digital Copy Image, de Fabio Belletti e Pierluigi Vannozzi. Circolo Culturale News. Modena, Italia. p.198

${ }^{14}$ ZIELINSKY, Siegfried: "Informe para la dramatización de una interfaz". En Arte en la era electrónica perspectivas de una nueva estética. Congreso Internacional. Goethe Institut, Diputació de Barcelona, Barcelona. 1997.p20.

15 "Production becomes a by-product and no an end in itself". SHERIDAN, Sonia L. en SIKKEMA, Brent. The Inner Landscape and the Machine: A Visual Studies Workshop Traveling Exhibition of the Work of Sonia Landy Sheridan. Visual Studies Workshop. Rochester, New York. 1974. 
teletransmisión facsímil que fue imprimiendo en tiempo real el rodaje de una pequeña batería de 1,5 voltios sobre el cristal. Este concepto es desarrollado en el arte digital donde "La forma de la obra contemporánea se extiende más allá de su forma material: es una amalgama, un principio aglutinante dinámico." ${ }^{16}$ dejando de ser un camino incuestionable hasta una objeto final.

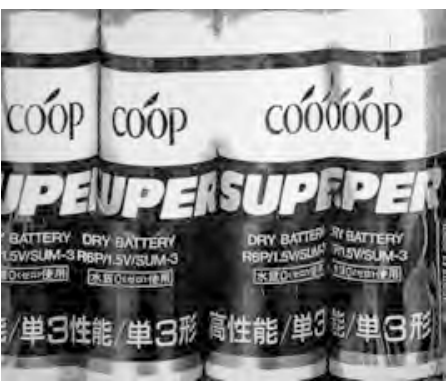

llustración 5. Hirotaka Mauryama (Marugiro).The faxed battery. Imagen enviada por fax. Impresión xerográfica. 1992. Colección MIDE

Otra de las particularidades que supone una ruptura con los paradigmas tradicionales del arte, relacionada con las problemáticas de la reproductibilidad técnica y que conectan con el arte digital es la naturaleza múltiple de estas obras, dejando atrás el concepto de obra única y aurática benjaminiana. La obra concebida por estas máquinas es siempre original, ya que pese a que la fotocopiadora fue creada para la copia de documentos, los artistas la utilizan para generar obras originales, entendiendo por original aquella obra nueva, que no es copia de otra, y por tanto, no está relacionada con los conceptos de plagio o copia como duplicado. Es precisamente el hecho de que en un primer momento se le denominó al movimiento Copy Art, lo que acarreó problemas conceptuales que en Europa trataron de salvar denominando a las obras xerografías originales.

Por otro lado, en muchas de las obras el proceso de copiado, es la forma de construcción de la obra gracias a su naturaleza capaz de producir gran numero de copias por minuto. Es decir, se genera un original y, posteriormente, esa obra se sitúa de nuevo sobre el cristal para ampliarla, reducirla, deformarla, degenerarla, moverla, etc., con el fin de conseguir la obra u obras finales. Es el caso del artista alemán Franz John y su animación de video Instant Copier animation, una película que realizó partiendo de un único original, a partir del cual creo todas las formas, deformaciones y movimientos. El propio artista ha manifestado que para él la copia (refiriéndose a las diferentes impresiones generadas de un mismo original) es lo transcendental: "El original es prácticamente nada, tienes que tirarlo a la basura, es sólo una estructura inicial muy aburrida. ${ }^{17} \mathrm{Y}$, finalmente, debemos aclarar que la máquina tiene un atributo como productora de múltiples que transgrede la unicidad, dando lugar a la imagen repetida e incluso infinita del arte digital. Ello no devalúa el original sino que transforma el valor adquisitivo de una obra en valor de exhibición. Como resultado, la obra de arte no va a la galería sino que se expone de modo independiente y promueve un intercambio artístico a través de colecciones privadas que artistas e interesados van coleccionando, comprando o intercambiando. Algo que, sin duda, se acerca al concepto de Museo Imaginario del novelista y teórico del arte André Malraux (1901-1976) que forma parte de la obra La Psychologie del arte (1951). El Museo Imaginario es una obra con 500 ilustraciones en la que Malraux expone su deseo de tener un museo donde gozar de obras reproducidas, luego piensa que, si sólo advertimos las obras que los museos exponen, tenemos una visión parcial de la historia del arte. Una idea que se fundamenta en el Museo Transportable de Marcel Duchamp, quién, en 1935, había realizado un museo portátil al que llamo Boîte-en-valise, una maleta donde tenía expuesta con reproducciones en miniatura, sus mejores obras. Esta transformación del valor adquisitivo al valor exhibitivo gracias a su multiplicidad y al uso de otros Medios ( como hizo el Mail art o el Fax Art) es la propia naturaleza del arte digital que, gracias sobre todo a Internet, y al concepto de museo virtual, pueden ampliar su visionado.

\section{EL MUSEO INTERNACIONAL DE ELECTROGRAFÍA. REFLEJO DE RUPTURAS Y ACTITUDES TRANSFORMADORAS}

Sólo unos pocos, sobre todo los propios artistas, han sabido valorar estas propuestas dentro del contexto de ruptura que promovían. Gracias a algunos de ellos, estas problemáticas expuestas pueden ser estudiadas en el único museo abierto que existe a nivel internacional y que se ocupa de la conservación y difusión de éste patrimonio: El Museo Internacional de Electrografía de Cuenca (MIDE). Fundado en 1990 y dirigido desde entonces por el catedrático y artista José Ramón Alcalá Mellado, este centro fue la primera respuesta museística al arte realizado con cualquier tipo de máquinas y procesos relacionados con las nuevas tecnologías de generación, reproducción y estampación de imágenes, como un museo abierto y dinámico, más allá de un simple contenedor de obra tradicional. Su creación fue asesorada por dos de los más importantes artistas de estas tecnologías: Christian Rigal, artista y profesor francés de la School of Visual Arts de Nueva York; y el artista alemán Klaus Urbons, quien crea el Müsem für Fotokopie en Mülheim (Alemania) que junto al MIDE eran los dos únicos museos en el mundo con este tipo de piezas, pero que actualmente está cerrado.

\footnotetext{
${ }^{16}$ BOURRIAUD, Nicolas: Estética relacional. Adriana Hidalgo editorial, Buenos Aries. 2008. p.21

${ }^{17}$ Entrevista realizada al artista en el programa Metrópolis n²90. Tv2- 08/02/1990.
} 
EI MIDE se funda como lab-museo, cuyo objetivo no sólo es la conservación de ese tipo de arte, sino que se convierte en un centro de investigación sobresaliente internacionalmente cuyas actuaciones han sido la creación de una mediateca especializada en ciencia, arte y nuevas tecnologías; de talleres financiados por empresas internacionales como Canon, Epson o Apple y la investigación entorno a los procesos electrográficos, los nuevos procesos gráficos; y el arte electrónico más puntero hasta el actual Media Art indagando las posibilidades de las tecnologías electrónicas y digitales. Además, una de sus características definitorias es su inclusión en el sistema universitario, pues trabajan o participan en él alumnos de la Facultad así como profesores, artistas o investigadores.

De este modo, en estos 25 años de existencia, el MIDE se convierte en un verdadero laboratorio de nuevas tecnologías dedicado a la gráfica digital y a la impresión y que ejemplifica perfectamente la transición entre lo analógico - digital con las tres colecciones que conforman su patrimonio: La colección de Arte Electrográfico, la Colección de Gráfica Digital y la Colección de Intangibles. Estas tres colecciones muestran la evolución desde las primeras fotocopias analógicas en blanco y negro hasta los grafismos electrónicos de la gráfica digital, pasando por el multimedia interactivo o las páginas web.

La vasta extensión del campo de actuación de los procesos electrográficos es la razón por la que, al tratar de analizar los hitos creativos producidos por los artistas dentro de este particular campo de creación, hace notar que existen tantos enfoques, actitudes diferentes adoptadas por estos frente al uso de los procesos gráficos y tecnologías de la imagen, como objetivos conceptuales y creativos existen en cada momento a lo largo de ese periodo histórico. Sin embargo, se pueden destacar distintas actitudes del artista que muestran el fundamento de lo virtual-digital actual.

La primera actitud destacable en estas propuestas que pueden verse en el MIDE es la de experimentar con la instantaneidad de la máquina automática que desmaterializa todo lo que está sobre el cristal simplemente con pulsar un botón para codificarlo bajo su propio metalenguaje. Son muchos los que como primer contacto con la máquina reproducen lo que tienen más cerca. El resultado son imágenes codificadas a través del propio lenguaje de la máquina: la texturización del tóner, la luz, la escasez de profundidad y la deformación producida por la gravedad al ser una producción horizontal.

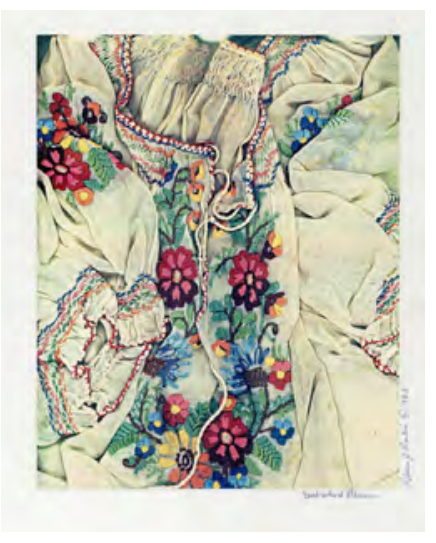

Ilustración 6. Rebeca Rackin. Embroidered Blouse. 1983. Colección MIDE

Otra de las actitudes destacables del artista es la de experimentar con su propio cuerpo produciéndose esa intersección a través de la membrana de la interfaz, de la naturaleza calida del cuerpo con la frialdad de la máquina. Es una acción de encuentro y contacto con la máquina y con sus iconografías resultantes en las que la imagen impresa es la parte que la máquina oculta ante el espectador al posicionarse el cuerpo sobre el cristal.

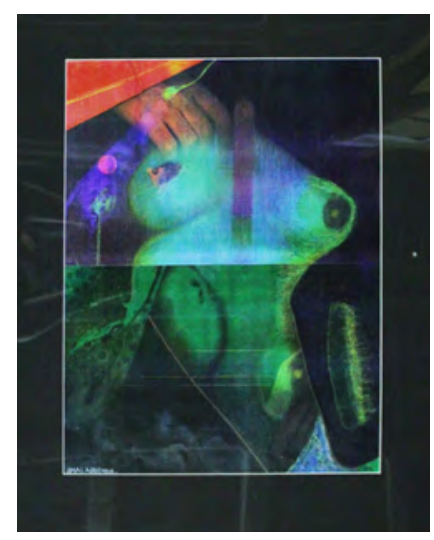

Ilustración 7. Amal Abdenour. Sin título. 1974. Colección MIDE 
La propia metodología procesual se convierte en actitud de experimentación donde el mínimo error de la máquina, ruptura de ésta o acaso del proceso, puede ser la mejor posibilidad de intervención artística o el más fascinante resultado iconográfico. Una actitud que tiene mucho que ver con el Glitch Art, y la pura experimentalidad a través del lenguaje de la máquina, cuando es el hombre quien tiene el poder de decidir si seguir las normas o subvertirlas y que aparezca el error estetizado. "De un modo extraño y misterioso, la copiadora es una <máquina mágica>. Encontrarás que muy a menudo el "accidente", lo "no planeado", y lo "inesperado" producen resultados que nunca habrías llegado a imaginar,18.
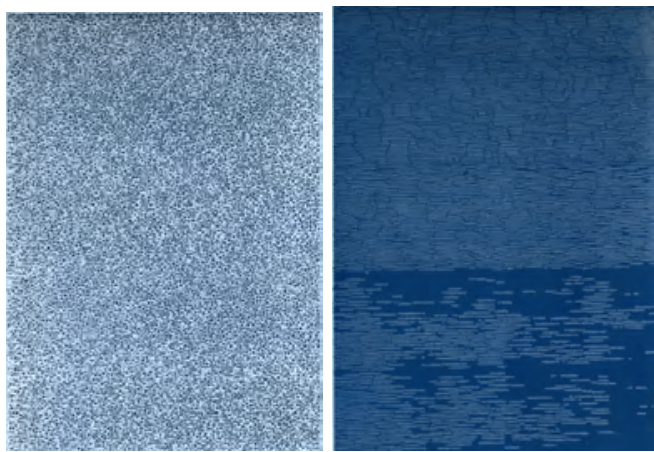

Ilustración 8. James Durand. Paisagge I\&II. 1985. Colección MIDE

Todas estas experiencias conducen a la necesidad de reproducir o hacer salir el tóner al espacio, de buscar la espacialidad del tóner. Es la reflexión que se genera a partir de la obra The Copied Gallery del artista Franz John, quién reprodujo punto a punto, bajo el ritmo de la máquina, las tres dimensiones de la sala de exposiciones elegida. El espectador se encuentra ante un espacio que bien puede ser predecesor de los entornos inmersivos de simulación virtual.
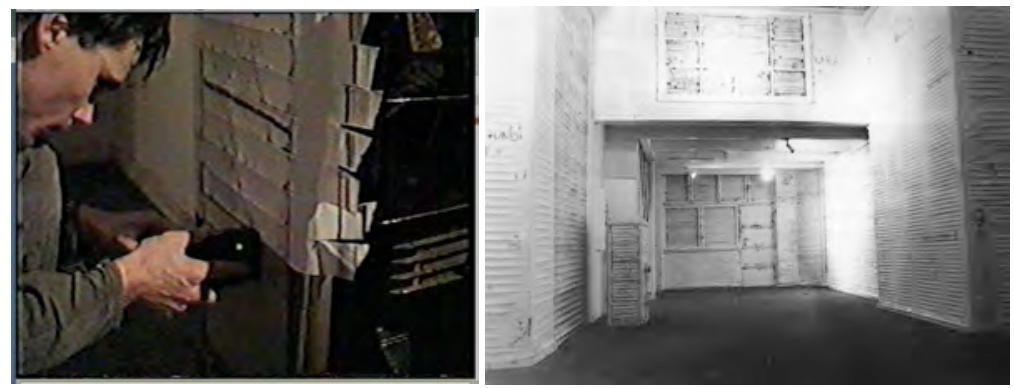

Ilustración 9. Franz John realizando la instalación The Copied Gallery (derecha). 1985. Colección MIDE

Consecuentemente, llega la necesidad de buscar la temporalidad del tóner, aunque ya en sí mismo el funcionamiento de esta máquina impone un ritmo específico en el barrido de la imagen. Es la máquina copiadora un antecedente de la holografía actual, como fotografía tridimensional abatida, pero que puede capturar las tres dimensiones gracias a su temporalidad. Esta introducción del espacio y el tiempo continua su evolución y es representada con la telemática en el fax, que permite crear de un lado del mundo y transmitirlo a otro instantáneamente, siendo tanto emisor como receptor necesarios para la consumación de la obra. Es la cavilación de la obra The faxed battery, del artista japonés Hirotaka Maruyama (Maruhiro) revisada con anterioridad.

\section{CONCLUSIÓN}

La existencia de una necesidad inmediata de realizar Arqueología de todos estos documentos, parte básica de la investigación artística en torno a unas prácticas artísticas en revalorización, obligaron al MIDE a buscar otras estrategias que permitieran su difusión. Esto, sumado a que problemáticas similares acaecían a otra serie de lab-museos creados con la fundación de la Facultad de Bellas Artes de Cuenca, provocó que en 2012 se unieran bajo el nombre de Colecciones y Archivos de Arte Contemporáneo de Cuenca (CAAC) con el fin de ofrecer una oferta artística común.

CAAC es actualmente un espacio de recursos patrimoniales y documentales fruto de las investigaciones desarrolladas por los distintos artistas-investigadores, que cualquiera que desee conocer las prácticas artísticas más experimentales, así como el origen de algunos

\footnotetext{
18 "In some strange and mysterious way, the copier is a <magical machine>. You will find that very often the "accident", the "unplanned", and the "unexpected" will produce results you could note even begin to imagine"FIRPO, Patrick; LESTER, Alexander; KATAYANAGI, Claudia: COPYART The first complete guide to the copy machine. Produced by Horseguard Lane Productions. Ltd. Richard Marek Publishers, New York. 1978. p.5
} 
de los paradigmas del Media Art actual, deberá tener contacto directo con estos materiales.

La puesta en funcionamiento y divulgación de las CAAC de Cuenca posee el aval del propio Ministerio de Economía y Competitividad, siéndole concedido un proyecto coordinado I+D de Excelencia en su última convocatoria (12/2103). El proyecto, liderado por el grupo de investigación "Interfaces Culturales; Arte y nuevos Medios" y dirigido por el catedrático José Ramón Alcalá Mellado, lleva por título: "Creación y Estudios de las CAAC (Colecciones y Archivos de Arte Contemporáneo) de Cuenca como modelo metodológico para una investigación de excelencia en Bellas Artes" y tiene prevista su duración hasta diciembre de 2016. Participan en él 19 investigadores pertenecientes a 5 universidades con 20 sexenios activos y está dotado con $40.000 €$ en costes directos y $8.400 €$ en indirectos. (REF.: HAR2013-48604-C2-1-P) En suma, a nivel particular, el MIDE posee otro proyecto I+D regional con fondos FEDER denominado "Las colecciones de arte electrográfico y digital del MIDE. Gestión, conservación, restauración y divulgación de sus fondos.", obtenido en la convocatoria de Proyectos plurianuales de investigación científica 2014-2017 y que está financiado con 149,057,00 €. (REF.: POII-2014002-P). El fin de ambos proyectos es que estos materiales, fondos y recursos sean clasificados, conservados y puestos a disposición de los investigadores, $y$, a partir de ello, pueda ser revisada la Historia de esta rara colección histórica del MIDE en el contexto del trabajo de las vanguardias que transitan del siglo $X X$ al XXI, en la que conceptos y adjetivos como desmaterialización, temporización de la materia, telemática, multiplicidad, hibridación, entre otros, se convierten en fundamentos referenciales y atemporales del arte actual.

\section{FUENTES REFERENCIALES}

BARBIERI, Daniele: Al di là del concettuale, dalla tecnica in poi. Presentación de la exposición Digital Copy Image de Fabio Belletti e Pierluigi Vannozzi. Circolo Culturale News. Modena, Italia. p.198

BOURRIAUD, Nicolas: Estética relacional. Adriana Hidalgo editorial, Buenos Aries. 2008. p.21

FIRPO, Patrick; LESTER, Alexander; KATAYANAGI, Claudia: COPYART The first complete guide to the copy machine. Horseguard Lane Productions, Ltd. Richard Marek Publishers, New York. 1978. p.10

GRAU, Olivier (ed.): Media Art Histories. The MIT Press, Cambrige, Massachussets / London, England. 2007. p.8

HUEMER, Peter: Photocopy Medium: From reproduction to production with analogue and digital photocopiers. 1998.

OLHAGARAY LLANOS, Néstor: Del video-arte al net-art. Editorial LOM, Santiago de Chile. 2002. p.9

SHERIDAN, Sonia L.: Art's Passionate Pilgrim. Hood Museum of Art, USA. 2009.

SHERIDAN, Sonia L.: Art at the Dawning of the Electronic Era. Generative Systems. Lonesome Press, Hanover. 2014. p.5

SIKKEMA, Brent. The Inner Landscape and the Machine: A Visual Studies Workshop Traveling Exhibition of the Work of Sonia Landy Sheridan. Visual Studies Workshop, Rochester, NY. 1974.

STEINBERG, Leo: El plano pictórico horizontal. En YATES, Steve (ed): Poéticas del espacio. Colección FotoGGrafía. 2002. p. 273

ZIELINSKY, Siegfried: "Informe para la dramatización de una interfaz". En Arte en la era electrónica perspectivas de una nueva estética. Congreso Internacional. Goethe Institut, Diputació de Barcelona, Barcelona. 1997.p20. 